\title{
Light intensity drives different growth strategies in two duckweed species: Lemna minor L. and Spirodela polyrhiza L. Schleiden
}

\author{
Małgorzata Strzałek $^{1}$, Lech Kufel $^{\text {Corresp. } 1}$ \\ ${ }^{1}$ Institute of Biological Sciences, Faculty of Sciences, Siedlce University of Natural Sciences and Humanities, Siedlce, Poland \\ Corresponding Author: Lech Kufel \\ Email address: lech.kufel@uph.edu.pl
}

Duckweed species Lemna minor and Spirodela polyrhiza are clonal plants with vegetative organs reduced to a frond and a root in $L$. minor or a frond and several roots in $S$. polyrhiza. They reproduce vegetatively by relatively rapid multiplication of their fronds. The habit of $S$. polyrhiza (large fronds with up to 21 roots) makes it a strong competitor among representatives of the family Lemnaceae, probably due to different resource-use strategies compared to small duckweed. In our study, light was the resource that affected the plants before and during the laboratory experiment. We sampled the plants from natural habitats differing in light conditions (open and shady) and grew them for 16 days in a thermostatic growth room at $22^{\circ} \mathrm{C}$ under a $16: 8$ photoperiod and three light intensities $\left(125,236,459 \mu \mathrm{mol}\right.$ photons $\left.\mathrm{m}^{-2} \mathrm{~s}^{-1}\right)$ to investigate the trade-off between frond enlargement and multiplication. Both species from the open habitat had higher growth rates based on the frond numbers and on surface area of fronds compared to plants from the shady habitat. They adopted different species-specific strategies in response to the experimental light conditions. The species size affected the growth rates in $L$. minor and $S$. polyrhiza. Spirodela polyrhiza grew slower than L. minor, but both species grew fastest at medium light intensity $\left(236 \mu \mathrm{mol} \mathrm{m} \mathrm{m}^{-2} \mathrm{~s}^{-1}\right)$. Lemna minor maintained the growth rates at high light intensity, while S. polyrhiza slowed down. Spirodela polyrhiza responded to deteriorating light conditions by increasing its frond surface area, thus optimising light capture. Lemna minor from the shady habitat enhanced light harvest by increasing chlorophyll a concentration, but did not invest more in frond enlargement than L. minor from the open habitat. Under shady conditions, $S$. polyrhiza is likely to achieve an advantage over $L$. minor due to the larger frond size of the former. Our findings suggest the existence of a trade-off between size and number in duckweed. 
1 Light intensity drives different growth strategies in 2 two duckweed species: Lemna minor L. and Spirodela 3 polyrhiza L. Schleiden

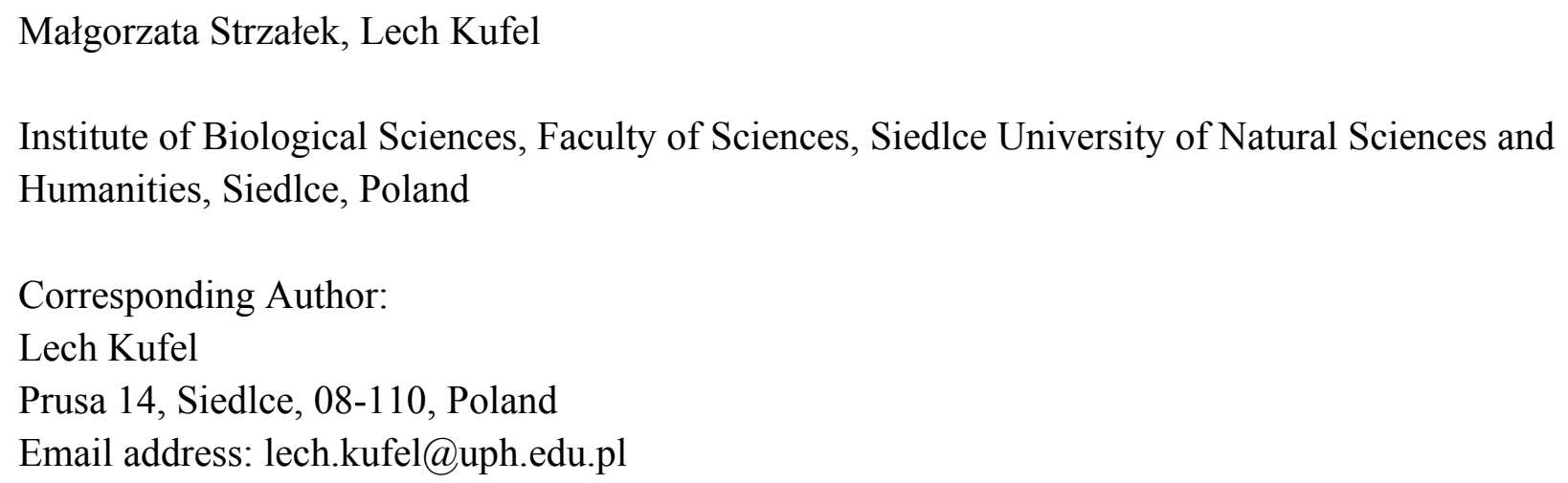




\section{Abstract}

18 Duckweed species Lemna minor and Spirodela polyrhiza are clonal plants with vegetative organs

19

20

21

22

23

24

25

26

27

28

29

30

31

32

33

34

35

36

37

38

39

40

41

42

43

44

45

46

47

48

49

50

51

52

53

54

55

56

reduced to a frond and a root in L. minor or a frond and several roots in S. polyrhiza. They reproduce vegetatively by relatively rapid multiplication of their fronds. The habit of $S$. polyrhiza (large fronds with up to 21 roots) makes it a strong competitor among representatives of the family Lemnaceae, probably due to different resource-use strategies compared to small duckweed. In our study, light was the resource that affected the plants before and during the laboratory experiment. We sampled the plants from natural habitats differing in light conditions (open and shady) and grew them for 16 days in a thermostatic growth room at $22^{\circ} \mathrm{C}$ under a $16: 8$ photoperiod and three light intensities $\left(125,236,459 \mu \mathrm{mol}\right.$ photons $\left.\mathrm{m}^{-2} \mathrm{~s}^{-1}\right)$ to investigate the trade-off between frond enlargement and multiplication. Both species from the open habitat had higher growth rates based on the frond numbers and on surface area of fronds compared to plants from the shady habitat. They adopted different species-specific strategies in response to the experimental light conditions. The species size affected the growth rates in $L$. minor and $S$. polyrhiza. Spirodela polyrhiza grew slower than L. minor, but both species grew fastest at medium light intensity $\left(236 \mu \mathrm{mol} \mathrm{m} \mathrm{m}^{-2} \mathrm{~s}^{-1}\right)$. Lemna minor maintained the growth rates at high light intensity, while $S$. polyrhiza slowed down. Spirodela polyrhiza responded to deteriorating light conditions by increasing its frond surface area, thus optimising light capture. Lemna minor from the shady habitat enhanced light harvest by increasing chlorophyll $a$ concentration, but did not invest more in frond enlargement than L. minor from the open habitat. Under shady conditions, $S$. polyrhiza is likely to achieve an advantage over L. minor due to the larger frond size of the former. Our findings suggest the existence of a trade-off between size and number in duckweed.

\section{Introduction}

Lemna minor L. and Spirodela polyrhiza L. Schleiden, belonging to the Lemnaceae family, are widespread clonal species known as duckweed (Landolt, 1986). They form free-floating mats in open and shady habitats of stagnant and slow-flowing freshwater, especially those rich in nutrients (Landolt, 1986; Kufel et al., 2012). Their vegetative organs are reduced to a flat leaflike frond with one root in L. minor or many roots (up to 21) in S. polyrhiza. The latter has fronds twice as large as those of L. minor and also the largest in the family (Ø 4-12 mm). The size of the fronds and even their shape depend on the external conditions (i.a. light intensity, photoperiod, nutrient concentrations, temperature) and genetic variability among clones (Landolt, 1986).

Both duckweed species reproduce mainly vegetatively by meristems inside lateral pouches. Daughter fronds grow alternately from two mother pouches and remain attached to the mother frond via stipes for some time, forming a colony. This method of propagation allows the duckweed to quickly colonise free spaces (Landolt, 1986; Lemon \& Posluszny, 2000; Ziegler et al., 2015; Acosta et al., 2021). As clonal plants, they avoid the trade-off between longevity and the rate of offspring production, but they may potentially sacrifice the size of fronds for their

Peer] reviewing PDF | (2021:08:64578:2:0:NEW 2 Dec 2021) 
57 numbers (Stuefer, van Hulzen \& During, 2002; Aarssen, 2008). According to the life history 58 theory, the large allocation of resources in size precludes a high reproduction rate and vice versa 59 (Stearns, 1992). Any plant strategy is affected by environmental conditions (Stuefer, van Hulzen 60 \& During, 2002). Therefore, one may expect that in open and disturbed habitats, a genet should 61 succeed by producing small but numerous daughter fronds, as opposed to undisturbed shady 62 habitats where the production of large fronds may be more beneficial. The rationale for these 63 suppositions is provided by the 'physical-space-niche size distribution' hypothesis that small 64 individuals use space and associated patchy resources more efficiently than large individuals, 65 while large plants provide higher fecundity (frond production) and a better ability to compete 66 (Aarssen, Schamp \& Pither, 2006).

67 Light is a key factor affecting the growth and reproduction of plants. The response of duckweed 68 to light availability depends on species, clone, ambient temperature and tissue nutrient supply. 69 Different light-dependent metabolic processes have different light requirements, which may additionally be affected by co-occurring stressors and biotic factors, e.g. competition (Landolt \& Kandeler, 1987; Valladares and Niinemets, 2008). In general, light saturation for growth rates is lower than for photosynthetic rates and ranges for different Lemnaceae species and clones from 5,000 to 15,000 lux (Landolt \& Kandeler, 1987), corresponding to a photosynthetic photon flux density (PPFD) of 68-203 $\mu \mathrm{mol}$ photons $\mathrm{m}^{-2} \mathrm{~s}^{-1}$ of cool white light (Thimijan \& Heins, 1983). At the same temperature, $S$. polyrhiza reached the maximum growth rate of 0.38 day $^{-1}$ at about

77

78

79

80

81

82

83

84

85

86

87

88

89

90

91

92

93

94

95

96 $150 \mu \mathrm{mol} \mathrm{m}^{-2} \mathrm{~s}^{-1}$, whereas L. minor needed more than twice as much light to reach the plateau of the growth curve at 0.41 day $^{-1}$ (Landolt \& Kandeler, 1987). In L. minor, high light intensity changes the composition of leaf pigments and increases plant biomass, frond size, root length, the content of proteins and starch (Landolt \& Kandeler, 1987; Lepeduš et al., 2020; Stewart et al., 2021). Chlorophyll $a$ is the main photosynthetic pigment that, together with chlorophyll $b$ and carotenoids, play an essential role in capturing light energy, and their ratios in leaves vary with light availability (Lepeduš et al., 2020; Stewart et al., 2021). Low PPFD is accompanied by a decrease in the chlorophyll $a: b$ ratio and an increases in total chlorophyll concentration (Paolacci, Harrison \& Jansen, 2018; Lepeduš et al., 2020; Stewart et al., 2021). Based on the composition of leaf pigments, Stewart et al. (2021) clustered duckweed species (Lemna gibba L. and L. minor) with heliophilous perennials and highly shade-tolerant evergreens, indicating their ability to grow under varying light conditions.

During our studies carried out in Stratiotes aloides L. stands (Kufel et al., 2010, 2012; Strzałek, Kufel \& Wysokińska, 2019), we observed the dominance of various Lemnaceae species in mixed-species communities growing among Stratiotes leaves, therefore we decided to conduct a series of experiments explaining the reasons for our field observations. This experiment tested how basic life history traits, such as growth rates measured by the surface area and the number of fronds in two duckweed species most commonly occurring in Stratiotes stands, L. minor and S. polyrhiza, are affected by light intensity prevailing both in their habitats and under experimental conditions. These traits may affect the outcome of interspecific competition in duckweed communities. The larger species further limit the size of the smaller species by reducing light and 
97 nutrients, and the smaller species constrain the larger species by reducing space for offspring 98 (Aarssen, 2008). We hypothesised that $L$. minor as a smaller species multiplicates faster than $S$. 99 polyrhiza and S. polyrhiza as a larger species invests more in enlarging its own fronds. The 100 species respond differently to experimental light intensities, and the effect depends on light 101 conditions in their natural habitats. Since Lemnaceae are used in wastewater phytoremediation, 102 biofuel production and animal and human nutrition (e.g. Cheng \& Stomp, 2009; Gupta \& 103 Prakash, 2013; Appenroth et al., 2017; Liu et al., 2019; Acosta et al., 2021), our results may have

104

105

106

107

108

109

110

111

112

113

114

115

116

117

118

119

120

121

122

123

124

125

126

127

128

129

130

131

132

133

134

135

136 more wide-ranging practical applications.

\section{Materials \& Methods} Sampled habitats

Plants for the experiment were collected in September 2019 from two locations - a small ( 0.06

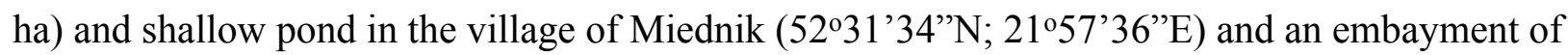
the Liwiec River near the town of Węgrów (52 $\left.23^{\prime} 51^{\prime \prime} \mathrm{N} ; 22^{\circ} 00^{\prime} 20^{\prime \prime} \mathrm{E}\right)$ in central-eastern Poland. Throughout the growing season, the water surface in the pond is shaded by the surrounding deciduous trees (mainly Acer spp. and Quercus robur L.) and shrubs shedding leaves for winter and by evergreen pines Pinus sylvestris L. (shady habitat), while that in the embayment is open (open habitat). Light intensity on a sunny sampling day was $2374 \mu \mathrm{mol}$ photons $\mathrm{m}^{-2} \mathrm{~s}^{-1}$ on the surface of the open water body and $121 \mu \mathrm{mol}$ photons $\mathrm{m}^{-2} \mathrm{~s}^{-1}$ on the shaded pond, while at the same time in the nearby open area it was $1980 \mu \mathrm{mol}$ photons $\mathrm{m}^{-2} \mathrm{~s}^{-1}$. Lemna minor and $S$. polyrhiza co-occurred at both sites.

\section{Experiment}

Bulk plant material was brought to the laboratory, washed with tap water, placed in containers (separately for each habitat) filled with synthetic N medium (Appenroth, Teller \& Horn, 1996) and left for a four-day preculture period (Appenroth, 2002). The plants divided into the species were then transferred to perforated transparent PET cups $(80 \mathrm{~mL}, \varnothing 70 \mathrm{~mm})$ immersed in cuvettes filled with $2 \mathrm{~L}$ of nutrient medium. Each cuvette contained ten cups with three colonies (9-13 fronds per cup) of L. minor and ten cups with two colonies (4-10 fronds per cup) of $S$. polyrhiza from a given habitat (shady or open) randomly distributed in the respective cuvette. In total, the number of cups was as follows: 10 replicates $x 2$ species $x 2$ habitats $\times 3$ light intensities $=120$. Three light intensities were applied with the following average PPFD values: low -125 , medium -236 and high $-459 \mu$ mol photons $\mathrm{m}^{-2} \mathrm{~s}^{-1}$ at a light:dark ratio of 16:8 h. The value of high light intensity was based on light saturation points for duckweed growth given in Landolt and Kandeler (1987). Light was provided by cool-white fluorescent tubes and its intensity was measured using a LI-192 sensor and a LI-250A light meter (LI-COR Inc., USA). The experiment was carried out in a thermostatic growth room at a temperature of $22^{\circ} \mathrm{C}$ and lasted 16 days. The nutrient medium was replaced in each cuvette every four days to inhibit algal development and to prevent nutrient depletion. The number of colonies and fronds in each cup was counted on the same days and the positions of the cups within the cuvettes were randomised. 
137 On days 1 and 16, fronds from each cup were photographed using a Sony a500 camera equipped

138

139

140

141

142

143

144

145

146

147

148

149

150

151

152

153

154

155

156

157

158

159

160

161

162

163

164

165

166

167

168

169

170

171

172

173

174

175

176

with macro lens DT 2.8/30. The obtained photos were processed using the Corel Draw Photo

Paint X5 package and then used to determine the surface area of all fronds using ImageJ software.

Plant performance was measured with two parameters. The first was the growth rate based on the number of fronds ( $\mathrm{rN}$ ) calculated according to the following equation describing exponential growth:

$$
\mathrm{rN}=\left(\operatorname{lnN}_{\mathrm{t}}-\ln \mathrm{n}_{0}\right) / \mathrm{t},
$$

where $\mathrm{N}_{0}$ and $\mathrm{N}_{\mathrm{t}}$ represent the number of fronds at the beginning and at the end of the experiment, respectively, and $t=16$ days. The second parameter, the growth rate based on the surface area of fronds ( $\mathrm{rS}$ ), was calculated using the following formula:

$$
\mathrm{rS}=\left(\ln \mathrm{S}_{\mathrm{t}}-\ln \mathrm{S}_{0}\right) / \mathrm{t} \text {, }
$$

where $S_{t}$ and $S_{0}$ are surface areas of fronds at the end and at the beginning of the experiment, respectively, and $\mathrm{t}=16$ days. The exponential model $\mathrm{rN}$ was checked using data from

measurements performed every four days from the beginning to the end of the experiment (five occasions).

Chlorophyll $a$ was extracted in $90 \%$ acetone from fresh plant weight (FW) at the beginning and at the end of the experiment in three replicates $(n=48)$. The extracts were measured spectrophotometrically and translated into chlorophyll concentrations following the equations provided by Golterman (1969). We adopted an extinction coefficient of $\mathrm{K}=89$ and replaced the filtrate volume by the FW sample in grams in the corresponding equations.

\section{Statistical analysis}

MANOVA and univariate $F$ tests were performed on the transformed data to test the effects of light intensities, habitats, plant species and factor interactions on the growth rates. The Box-Cox transformation normalised the data distribution and homogenised the variance. Three-way ANOVA $(3 \times 2 \times 2)$ was applied to test differences between chlorophyll $a$ concentrations in plant tissues. One-way ANOVA was used to test differences between the frond sizes in the plant species from different habitats at the beginning of the experiment. MANOVA and ANOVA were followed by Tukey multiple comparison test. Due to the lack of normality (Shapiro-Wilk test) and/or variance heterogeneity (Bartlett test), Kruskal-Wallis ANOVA and post-hoc Dunn test were used for differences between the growth rates $(\Delta r=r S-r N)$, frond sizes and the frond size increment $\left(\mathrm{S}_{\text {end }} / \mathrm{S}_{\text {start }}=\right.$ frond surface area at the end of the experiment/frond surface area at the beginning of the experiment). Lines of best fit were obtained using nonlinear and linear regressions where appropriate. To meet the assumptions of linear regression, two outliers were removed from the analysis. A significance level of 0.05 was assumed. All statistical analyses were conducted using Statistica 13.3 (TIBCO Software Inc.). The chlorophyll a concentrations presented in the Results section are mean values and their standard deviations.

\section{Results}


177 The number of fronds in all experimental light conditions increased with time, and the changes

178

179

180

181

182

183

184

185

186

187

188

189

190

191

192

193

194

195

196

197

198

199

200

201

202

203

204

205

206

207

208

209

210

211

212

213

214

215

216

were well fitted to the exponential model - see examples presented in Fig. 1.

MANOVA identified three factors and two interactions as significant for the growth rates based on the surface area of fronds (rS) and the number of fronds (rN) in L. minor and S. polyrhiza (Table 1). Univariate $\mathrm{F}$ tests revealed that $\mathrm{rS}$ and $\mathrm{rN}$ for both species, irrespective of habitat, were highest at medium light intensity $\left(\mathrm{F}_{2,108}=14, \mathrm{p}<0.001\right.$ and $\mathrm{F}_{2,108}=22, \mathrm{p}<0.001$ for $\mathrm{rS}$ and rN, respectively; Fig. 2). Plants from the open habitat performed better than the duckweed from the shade ( $\left.r S: \mathrm{F}_{1,108}=351, \mathrm{p}<0.001 ; \mathrm{rN}: \mathrm{F}_{1,108}=157, \mathrm{p}<0.001\right)$ and S. polyrhiza grew slower than L. minor (rS: $\mathrm{F}_{1,108}=84, \mathrm{p}<0.001 ; \mathrm{rN} \mathrm{F}_{1,108}=69, \mathrm{p}<0.001$ ). Although both duckweed species had their optima for $\mathrm{rS}$ and $\mathrm{rN}$ at about $236 \mu$ mol photons $\mathrm{m}^{-2} \mathrm{~s}^{-1}$ (medium light intensity), they adopted different strategies in response to experimental light conditions ( $\mathrm{rS}$ : $\left.\mathrm{F}_{2,108}=3, \mathrm{p}=0.037 ; \mathrm{rN}: \mathrm{F}_{2,108}=20, \mathrm{p}<0.001\right)$. Spirodela polyrhiza fronds, irrespective of habitat, grew more slowly at high light intensity (Tukey test: $\mathrm{p}<0.001$, $\mathrm{df}=108$ for $\mathrm{rS}$ and $\mathrm{p}<$ $0.001, \mathrm{df}=108$ for $\mathrm{rN}$ ), while $L$. minor performed at the same rate at medium light intensity (Tukey test: $\mathrm{p}=0.37, \mathrm{df}=108$ for $\mathrm{rS}$ and $\mathrm{p}=0.73$, $\mathrm{df}=108$ for $\mathrm{rN}$; Fig. 2). The interaction between the duckweed species and their habitats was significant only for $r N\left(F_{1,108}=35, p<\right.$ 0.001 ). Both species from the shade multiplicated $(\mathrm{rN})$ at the same rate (Tukey test: $\mathrm{p}=0.32$, $\mathrm{df}$ $=108$ ) and slower than the plants from the open habitat (Tukey test: $\mathrm{p}<0.019, \mathrm{df}=108$ ). The fastest multiplication was observed for L. minor from the open habitat (Tukey test: $\mathrm{p}<0.001$, df $=108$ ) and then for S. polyrhiza from the open habitat (Tukey test: $\mathrm{p}<0.001, \mathrm{df}=108$ ). The mean values of $\mathrm{rN}$ and $\mathrm{rS}$ and their standard deviations are presented in Table S1.

In both L. minor and S. polyrhiza, the growth rate based on the frond surface area (rS) was higher than that based on the number of fronds at all light intensities (Fig. 2). This means that the multiplication was accompanied by an enlargement of plant fronds. The difference $\Delta \mathrm{r}=\mathrm{rS}-\mathrm{rN}$ was always positive and may be considered here as a relative investment of plants in increasing the size of fronds rather than their multiplication. In general, the investment of the species from the same habitat did not differ significantly with respect to light intensity (Table 2). The relation between $\Delta \mathrm{r}$ and the habitat was observed only for S. polyrhiza. At the beginning of the experiment, fronds of S. polyrhiza from the shade were on average 1.3 times larger than those from the open habitat (one-way ANOVA, $\mathrm{F}_{1,58}=25.66, \mathrm{p}<0.001$ ). Spirodela polyrhiza from the open habitat responded with frond enlargement to the deterioration of light conditions in the culture relative to the natural habitat and doubled the mean frond size by the end of the experiment (Table 2; Fig. 3). Interspecific differences in the investment were statistically significant only within the shady habitat and low light intensity: L. minor from the shade invested more in its growth than co-occurring S. polyrhiza (Dunn test: $\mathrm{p}=0.005, \mathrm{n}=120$ ). The regression of the frond size increment on $\mathrm{rN}$ was significant for both duckweed species regardless of the habitat they came from (Fig. 4). This relationship was least pronounced in $L$. minor from the shade $(\beta=-0.37)$ and most pronounced in co-occurring S. polyrhiza $(\beta=-0.61)$. In the case of duckweed from the open habitat, $\beta$ had similar values ( -0.48 for $L$. minor and 0.40 for S. polyrhiza). The regression analysis showed that the multiplication of fronds reduced

Peer) reviewing PDF | (2021:08:64578:2:0:NEW 2 Dec 2021) 
217 their enlargement mainly in L. minor from the open habitat. Spirodela polyrhiza from the shade

218 had sufficiently large fronds at the beginning of the experiment that it did not need to enlarge

219 them further and could allocate resources to multiplication. The relatively low coefficients of

220 determination were due to considerable variation in the size and/or number of fronds within low

221 and high light intensities ( $\mathrm{CV}=10-16 \%)$.

222 In addition, we analysed the initial and final concentrations of chlorophyll $a$ in the plants studied.

223 Three-way ANOVA showed a significant effect of light intensity, plant habitat, and the latter

224 together with species on chlorophyll $a$ concentrations (Table 3). The duckweed growing under

225 low light intensity had the highest concentration of the pigment $\left(1.089 \pm 0.106 \mathrm{mg} \mathrm{g}^{-1} \mathrm{FW}\right)$. The

226 increase in light intensity caused a gradual decrease in the concentration of chlorophyll $a$ in plant

227 tissues $\left(0.904 \pm 0.118\right.$ at medium light intensity, $0.816 \pm 0.101 \mathrm{mg} \mathrm{g}^{-1} \mathrm{FW}$ at high light intensity)

228 to the initial level recorded at the beginning of the experiment $\left(0.838 \pm 0.111 \mathrm{mg} \mathrm{g}^{-1} \mathrm{FW}\right)$.

229 Despite different light intensities used, plants from the shade contained on average more

230 chlorophyll $a\left(0.955 \pm 0.145 \mathrm{mg} \mathrm{g}^{-1} \mathrm{FW}\right)$ than those from the open habitat $\left(0.869 \pm 0.149 \mathrm{mg} \mathrm{g}^{-1}\right.$

231 FW). Habitat had no effect on the concentration of chlorophyll $a$ in S. polyrhiza, while L. minor

232 from the shady habitat had the highest chlorophyll $a$ concentration of all plants studied (Fig. 5).

233

234 Discussion

235 The response of Lemnaceae to light intensity depends on many factors, including species, clone, 236 temperature, nutrient concentrations, $\mathrm{CO}_{2}$ supply and light quality (Landolt \& Kandeler, 1987).

237 Both species, L. minor and S. polyrhiza, are small compared to other representatives of

238 angiosperms, but even small differences in size can give a competitive advantage, especially

239 under the conditions of competition for light, and generate different life strategies (Aarssen,

240 Schamp \& Pither 2006). In our study, S. polyrhiza, being larger, grew slower than smaller $L$.

241 minor, which was also noted by Lemon, Posluszny \& Husband (2001). Their study revealed that

242 S. polyrhiza retained daughter fronds longer than L. minor and produced only a few new fronds

243 during that time. Such long retention results in larger fronds and slower population growth.

244 These results are consistent with competitive strategies of larger species that take advantage of

245 their size, while smaller species like L. minor gain a numerical advantage (Aarssen, 2008). The

246 multiplication of fronds in duckweed can be regarded as equivalent to seed production in

247 sexually propagating species. The latter is higher in small plants than in large ones (Aarssen,

248 Schamp \& Pither 2006), thus it is not surprising that in our experiment L. minor had a higher $\mathrm{rN}$

249 than S. polyrhiza.

250 In our study, experimental light conditions affected the growth rates in both duckweed species,

251 indicating species-specific light strategies. Both species grew fastest at medium light intensity

252 (about $236 \mu \mathrm{mol}$ photons $\mathrm{m}^{-2} \mathrm{~s}^{-1}$ ), which slightly exceeded the upper limit of light saturation

253 range of 15,000 lux (about $203 \mu \mathrm{mol}$ photons $\mathrm{m}^{-2} \mathrm{~s}^{-1}$ ) for duckweed growth under continuous

254 light (Landolt \& Kandeler, 1987). The higher light intensity resulted in a marked reduction in the

255 growth rate of $S$. polyrhiza as determined by the number of fronds and a slightly smaller decrease

256 in the growth rate based on the frond surface area, while L. minor maintained similar growth

Peer] reviewing PDF | (2021:08:64578:2:0:NEW 2 Dec 2021) 
257

258

259

260

261

262

263

264

265

266

267

268

269

270

271

272

273

274

275

276

277

278

279

280

281

282

283

284

285

286

287

288

289

290

291

292

293

294

295

296

rates. The clear differences in light requirements of both species are consistent with the results presented by Landolt \& Kandeler (1987) according to which $S$. polyrhiza achieved its optimal growth rate at about $250 \mu \mathrm{mol}$ photons $\mathrm{m}^{-2} \mathrm{~s}^{-1}$, while $L$. minor needed about $100 \mu \mathrm{mol}$ photons $\mathrm{m}^{-2} \mathrm{~s}^{-1}$ more to reach its optimum. In duckweed growth inhibition tests, $100 \mu \mathrm{mol}$ photons $\mathrm{m}^{-2}$ $\mathrm{s}^{-1}$ of continuous light is recommended (e.g. ISO 20079, 2005 cited in Ziegler et al., 2015), which corresponds to the low light intensity applied in our experiment. Our clones of both species performed better under the higher light level and a 16:8 photoperiod, but multiplicated more slowly than under axenic conditions. In the following discussion, we will avoid direct comparisons with data from the literature because, as argued by Ziegler et al. (2015), they can only apply to the same clones cultivated under the same conditions.

We showed that light conditions in the natural habitat of duckweed species affect their growth rate as determined by the number of fronds, and thus our findings may confirm that this rate reflects the adaptation of clones to local conditions (however, see caveats raised by Ziegler et al., 2015). The adaptation may involve genetic modifications of light-dependent metabolic pathways in plants. However, understanding its mechanism was not a goal of our study. We found that both species from the open habitat multiplicated faster than duckweed from the shady habitat. Our results showed different strategies of growth investments in L. minor and S. polyrhiza depending on habitat for S. polyrhiza and experimental light intensities for L. minor. Spirodela polyrhiza from the open habitat had considerably smaller fronds compared to plants from the shade and enlarged them during the experiment in response to a reduction of ambient light. This is also evidence for phenotypic plasticity of $S$. polyrhiza in adapting to local environmental conditions. The enlargement of the relatively large fronds appears to be sufficient for them to thrive and did not require an additional increase in chlorophyll $a$ concentration in their tissues to optimise light capture. In contrast, L. minor from both habitats invested nearly equally in the growth of fronds at the same light intensity. Living in prolonged shade was associated with maintaining a rather high concentration of chlorophyll $a$ in the tissues of this small species. Our findings contradict the conclusion of Landolt \& Kandeler (1987) that high light intensities promote frond enlargement. It should be noted that plants from the shady habitat in our study adjusted to higher experimental light intensities, while plants from the open habitat adjusted to low light intensities. The response of plants to shading involves a variety of mechanisms ranging from structural ones related to plant habit to molecular changes. Increasing the surface area of assimilatory organs (fronds) and remodelling the photosynthetic apparatus to capture sufficient light energy to thrive are among them (Valladares and Niinemets, 2008; Lepeduš et al., 2020; Stewart et al., 2021). Similar to the study by Lepeduš et al. (2020) on L. minor, exposure to higher light intensity during our experiment was associated with a decrease in chlorophyll $a$ concentrations in both duckweed species.

Our results indicate that there is an inverse relationship between the multiplication rate and frond size increment in both $L$. minor and S. polyrhiza, but two of the four regression models were at the limit of statistical significance. This was due to intensive multiplication with simultaneous frond enlargement in S. polyrhiza from the open habitat and fairly slow multiplication and little 
297

298

299

300

301

302

303

304

305

306

307

308

309

310

311

312

313

314

315

316

317

318

319

320

321

322

323

324

325

326

327

328

329

330

331

332

333

334

335

336

frond enlargement in L. minor from the shady habitat. Clonality allows for economical propagation of infinitely long-lived genets without producing large adults and fertilising ovules (Aarssen, 2008).

Apart from Landolt's monographs (Landolt, 1986; Landolt \& Kandeler, 1987), there are few papers comparing the traits of these two common duckweed species, i.e. L. minor and $S$.

polyrhiza (Bergmann et al., 2000; Lemon \& Posluszny, 2000; Lemon, Posluszny \& Husband, 2001; Kufel et al., 2012; Ziegler et al., 2015; Acosta et al., 2021). Most of the studies cited herein concern clones cultivated under axenic conditions, which have never been in contact with their natural environment. In our research, we used plants freshly collected in the field to bring the experimental conditions closer to the real environment.

\section{Conclusions}

Our results indicate that the species size affects the growth rates in L. minor and S. polyrhiza. As hypothesised, L. minor being a smaller species performed better than larger S. polyrhiza, and light conditions in their natural habitats and in the laboratory modified the studied traits. Plants from the open habitat multiplicated faster than those from the shady habitat, and the medium light intensity was optimal for the growth rate of both duckweed species. Spirodela polyrhiza showed high plasticity in terms of frond size, which increased under reduced light availability. Lemna minor from the shady habitat enhanced light harvest by increasing chlorophyll $a$ concentration, but did not invest more in frond enlargement than L. minor from the open habitat. The inverse relationship between the rate of multiplication and frond enlargement suggests a trade-off between size and number in both duckweed species. Our results contribute to the knowledge about factors affecting duckweed communities and suggest that under shaded conditions $S$. polyrhiza is likely to achieve an advantage over L. minor due to the larger frond size of the former.

\section{Acknowledgements}

We are grateful to Elżbieta Biardzka for her help in the chemistry laboratory and to Dr. Józef Klocek for making the growth room of the Institute of Biological Studies available .

\section{References}

\section{Acosta K, Appenroth K-J, Borisjuk L, Edelman M, Heinig U, Jansen MAK, Oyama T,} Pasaribu B, Schubert I, Sorrels S, Sree KS, Xu S, Michael TP, Lam E. 2021. Return of the Lemnaceae: duckweed as a model plant system in the genomics and postgenomics era. The Plant Cell 33: 3207-3234. DOI 10.1093/plcell/koab189.

Appenroth K-J. 2002. Co-action of temperature and phosphate in inducing turion formation in Spirodela polyrhiza (Great duckweed). Plant, Cell and Environment 25: 1079-1085. DOI 10.1046/j.1365-3040.2002.00885.x.

Appenroth K-J, Teller S, Horn M. 1996. Photophysiology of turion formation and germination in Spirodela polyrhiza. Biologia Plantarum 38: 95-106. DOI 10.1007/BF02879642. 
337 Appenroth K-J, Sree KS, Böhm V, Hammann S, Vetter W, Leiterer M, Jahreis G. 2017.

338 Nutritional value of duckweeds (Lemnaceae) as human food. Food Chemistry 217: 266-273.

339 DOI 10.1016/j.foodchem.2016.08.116.

340 Aarssen LW. 2008. Death without sex - the 'problem of the small' and selection for

341 reproductive economy in flowering plants. Evolutionary Ecology 22: 279-298. DOI

342 10.1007/s10682-007-9170-z.

343 Aarssen LW, Schamp BS, Pither J. 2006. Why are there so many small plants? Implications

344 for species coexistence. Journal of Ecology 94: 569-580. DOI 10.1111/j.1365-

345 2745.2006.01128.x.

346 Bergmann BA, Cheng J, Classen J, Stomp A-M. 2000. In vitro selection of duckweed

347 geographical isolates for potential use in swine lagoon effluent renovation. Bioresource

348 Technology 73: 13-20. DOI 10.1016/S0960-8524(99)00137-6.

349 Cheng JJ, Stomp AM. 2009. Growing duckweed to recover nutrients from wastewaters and for

350 production of fuel ethanol and animal feed. CLEAN-Soil Air Water 37: 17-26. DOI

351 10.1002/clen.200800210.

352 Golterman HL. 1969. Methods for Chemical Analyses of Fresh Waters. Blackwell

353 Scientific Publications, Oxford, Edinburgh, UK.

354 Gupta C, Prakash D. 2013. Duckweed: an effective tool for phytoremediation. Toxicological \&

355 Environmental Chemistry 95: 1256-1266. DOI 10.1080/02772248.2013.879309.

356 Kufel L, Strzałek M, Konieczna A, Izdebska K. 2010. The effect of Stratiotes aloides L. and

357 nutrients on the growth rate of Lemna minor L. Aquatic Botany 92: 168-172. DOI

358 10.1016/j.aquabot.2009.11.005.

359 Kufel L, Strzałek M, Wysokińska U, Biardzka E, Oknińska S, Ryś K. 2012. Growth

360 rate of duckweeds (Lemnaceae) in relation to the internal and ambient nutrient concentrations -

361 testing the Droop and Monod models. Polish Journal of Ecology 60: 241-249.

362 Landolt E. 1986. The family of Lemnaceae - a Monographic Study Vol. 1. Veroffentlichungen

363 des Geobotanischen Institutes der Eidgenossischen Technischen Hochschule, Stiftung Rubel,

364 Zürich, Switzerland.

365 Landolt E, Kandeler R. 1987. The family of Lemnaceae - a Monographic Study Vol. 2.

366 Veroffentlichungen des Geobotanischen Institutes der Eidgenossischen Technischen Hochschule,

367 Stiftung Rubel, Zürich, Switzerland.

368 Lemon GD, Posluszny U. 2000. Comparative shoot development and evolution in the

369 Lemnaceae. International Journal of Plant Sciences 161: 733-748. DOI 10.1086/314298.

370 Lemon GD, Posluszny U, Husband BC. 2001. Potential and realized rates of vegetative

371 reproduction in Spirodela polyrhiza, Lemna minor and Wolffia borealis. Aquatic Botany 70: 79-

372 87. DOI 10.1016/S0304-3770(00)00131-5.

373 Lepeduš H, Vidaković-Cifrek Ž, Šebalj I, Antunović Dunić J, Cesar V. 2020. Effects of low

374 and high irradiation levels on growth and PSII efficiency in Lemna minor L. Acta Botanica

375 Croatica 79: 185-192. DOI 10.37427/botcro-2020-016. 
376 Liu Y, Chen X, Wang X, Fang Y, Zhang Y, Huang M, Zhao H. 2019. The influence of

377 different plant hormones on biomass and starch accumulation of duckweed: A renewable

378 feedstock for bioethanol production. Renewable Energy 138: 659-665. DOI

379 10.1016/j.renene.2019.01.128.

380 Pagliuso D, Grandis A, Igarashi ES, Lam E, Buckeridge MS. 2018. Correlation of apiose 381 levels and growth rates in duckweeds. Frontiers in Chemistry 6: 291. DOI

$38210.3389 /$ fchem.2018.00291.

383 Paolacci S, Harrison S, Jansen MAK. 2018. The invasive duckweed Lemna minuta Kunth

384 displays a different light utilisation strategy than native Lemna minor Linnaeus. Aquatic Botany

385 146: 8-14. DOI 10.1016/j.aquabot.2018.01.002.

386 Stearns SC. 1992. The Evolution of Life Histories. Oxford University Press, UK.

387 Stewart JJ, Adams WW III, López-Pozo M, Doherty Garcia N, McNamara M, Escobar

388 CM, Demmig-Adams B. 2021. Features of the duckweed Lemna that support rapid growth 389 under extremes of light intensity. Cells 10: 1481. DOI 10.3390/cells10061481.

390 Stuefer JF, van Hulzen JB, During HJ. 2002. A genotypic trade-off between the number and

391 size of clonal offspring in the stoloniferous herb Potentilla reptans. Journal of Evolutionary

392 Biology 15: 880-884. DOI 10.1046/j.1420-9101.2002.00435.x.

393 Strzałek M, Kufel L, Wysokińska U. 2019. How does Stratiotes aloides L. affect the growth

394 and turion formation of Spirodela polyrhiza (L.) Schleiden? Aquatic Botany 154: 45-52. DOI

395 10.1016/j.aquabot.2019.01.001.

396 Thimijan RW, Heins RD. 1983. Photometric, radiometric, and quantum light units of measure:

397 A review of procedures for interconversion. HortScience 18: 818-822.

398 Valladares F, Niinemets Ü. 2008. Shade tolerance, a key plant feature of complex nature and 399 consequences. Annual Review of Ecology, Evolution, and Systematics 39: 237-257. DOI 400 10.1146/annurev.ecolsys.39.110707.173506.

401 Wedge RM, Burris JE. 1982. Effects of light and temperature on duckweed photosynthesis.

402 Aquatic Botany 13: 133-140. DOI 10.1016/0304-3770(82)90047-X.

403 Yin Y, Yu C, Yu L, Zhao J, Sun C, Ma Y. 2015. The influence of light intensity and 404 photoperiod on duckweed biomass and starch accumulation for bioethanol production.

405 Bioresource Technology 187: 84-90. DOI 10.1016/j.biortech.2015.03.097.

406 Ziegler P, Adelmann K, Zimmer S, Schmidt C, Appenroth K-J. 2015. Relative in vitro

407 growth rates of duckweeds (Lemnaceae) - the most rapidly growing higher plants. Plant Biology

40817 (Suppl. 1): 33-41. DOI 10.1111/plb.12184. 


\section{Figure 1}

Increasing number of fronds during the experiment fitted to an exponential model.

Data represent plants from the open and shady habitats grown at low light intensity $(n=10)$.
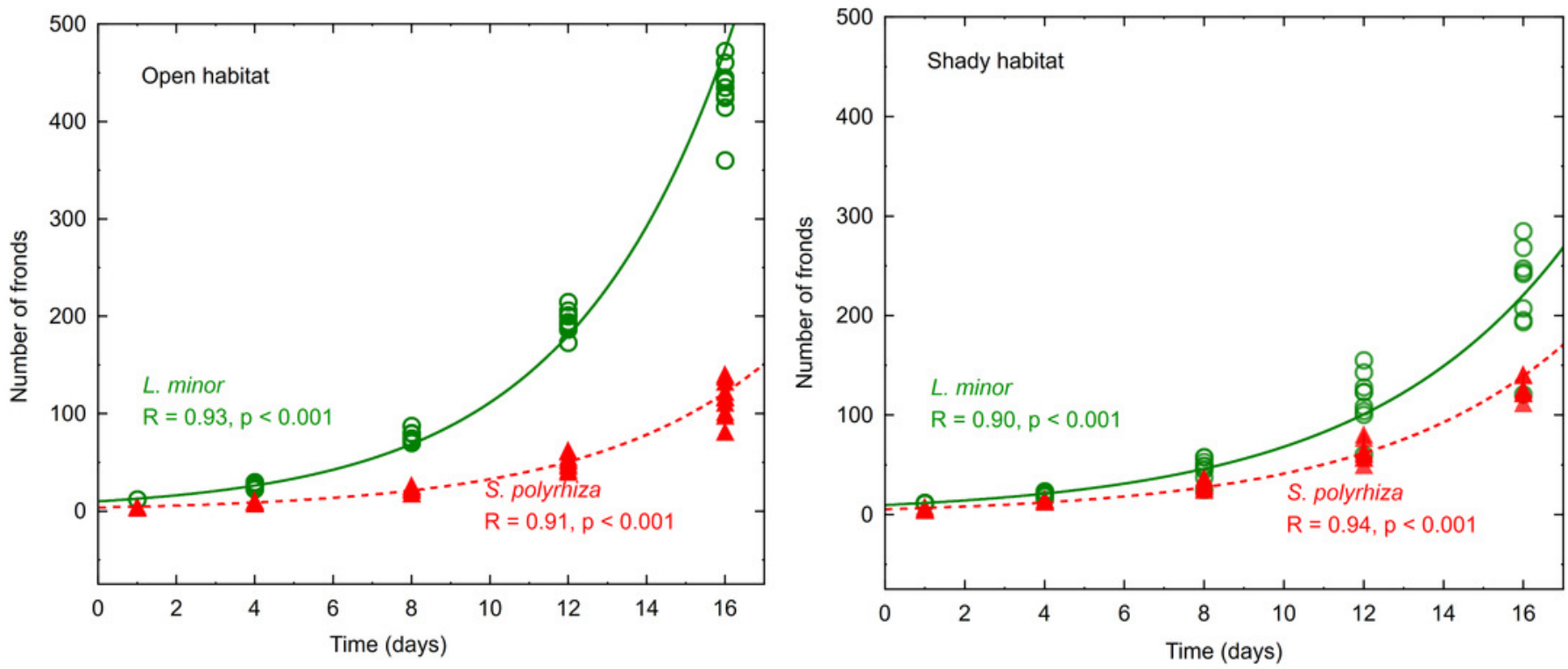
Figure 2

Growth rates as determined by the surface area of fronds ( $\mathrm{rS}$ ) and the number of fronds (rN) in L. minor and S. polyrhiza at different light intensities. Each box combines data from both habitats.

Different letters denote statistically significant differences in Tukey test ( $p<0.05, n=20$ ) following MANOVA.
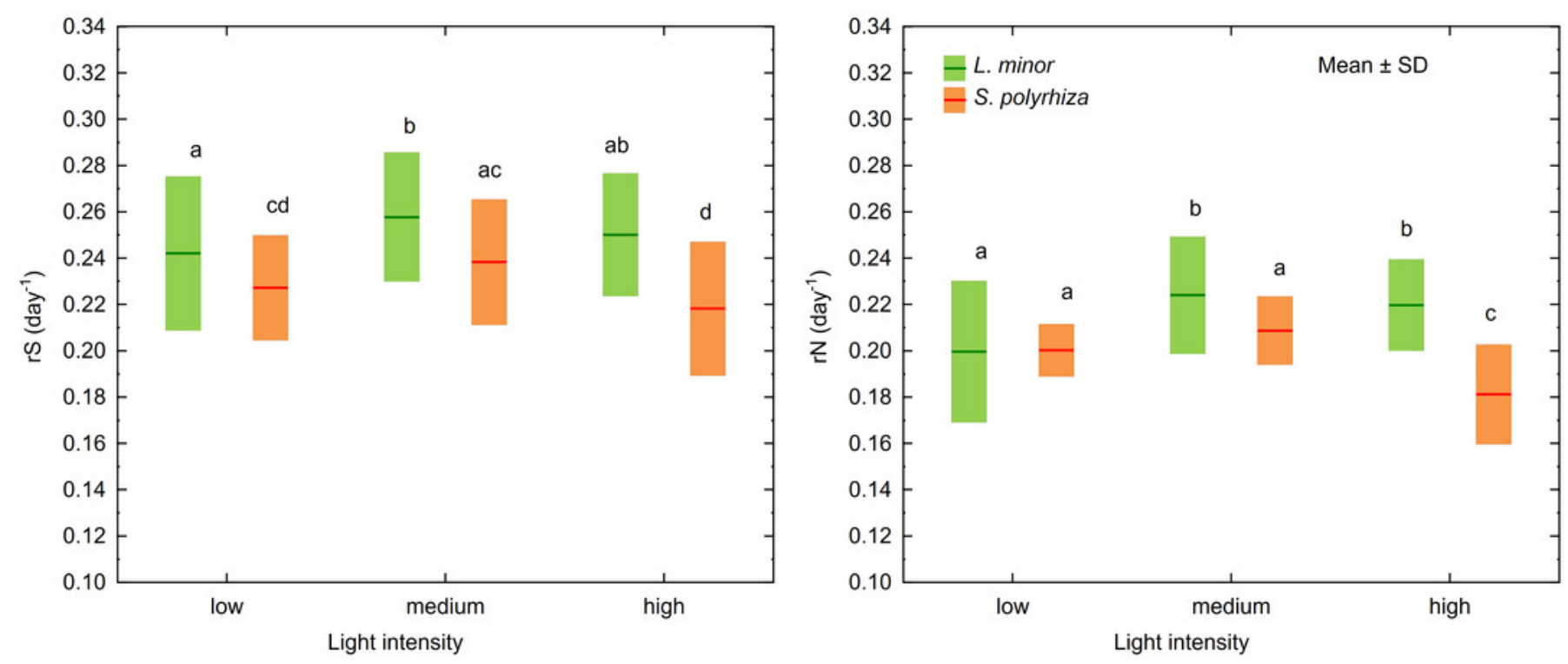
Figure 3

Increase in the surface area of fronds between the start $\left(\mathrm{S}_{\text {start }}\right)$ and the end $\left(\mathrm{S}_{\text {end }}\right)$ of the experiment in relation to the habitat of $L$. minor and S. polyrhiza. Each box combines data from three light intensities.

Different letters denote statistically significant differences between species from the two habitats in Dunn test $(p<0.01)$ following Kruskal-Wallis ANOVA $(H 3,120=58.60, p<0.001)$.

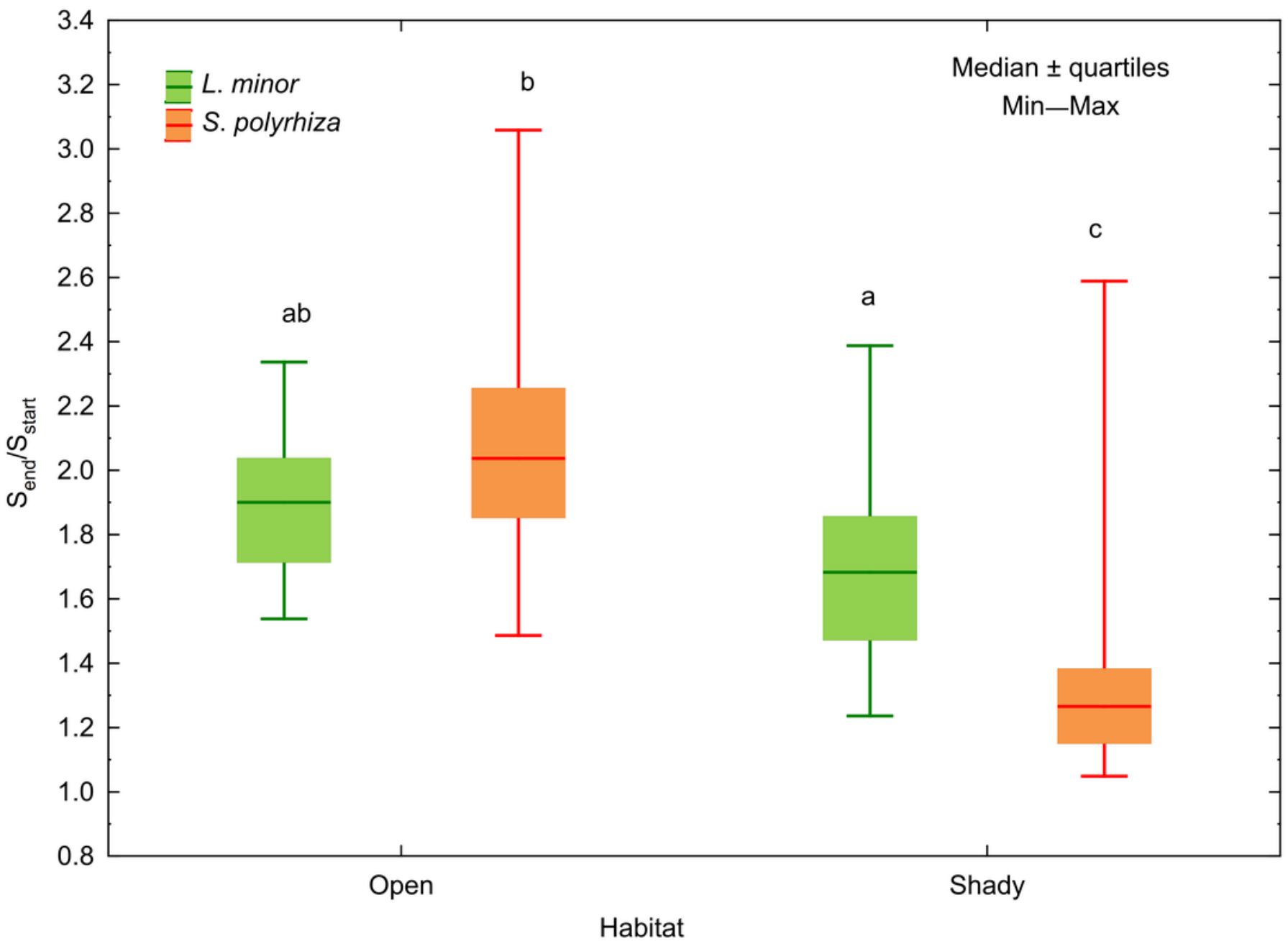


Figure 4

Regression lines of frond size increments $\left(\mathrm{S}_{\text {end }} / \mathrm{S}_{\text {start }}\right)$ on the growth rate based on the number of fronds in L. minor and S. polyrhiza from two habitats $(n=30)$.

$\mathrm{S}_{\text {start }}$ indicates the surface area of fronds at the beginning of the experiment, $\mathrm{S}_{\text {end }}$ indicates the surface area of fronds at the end of the experiment.
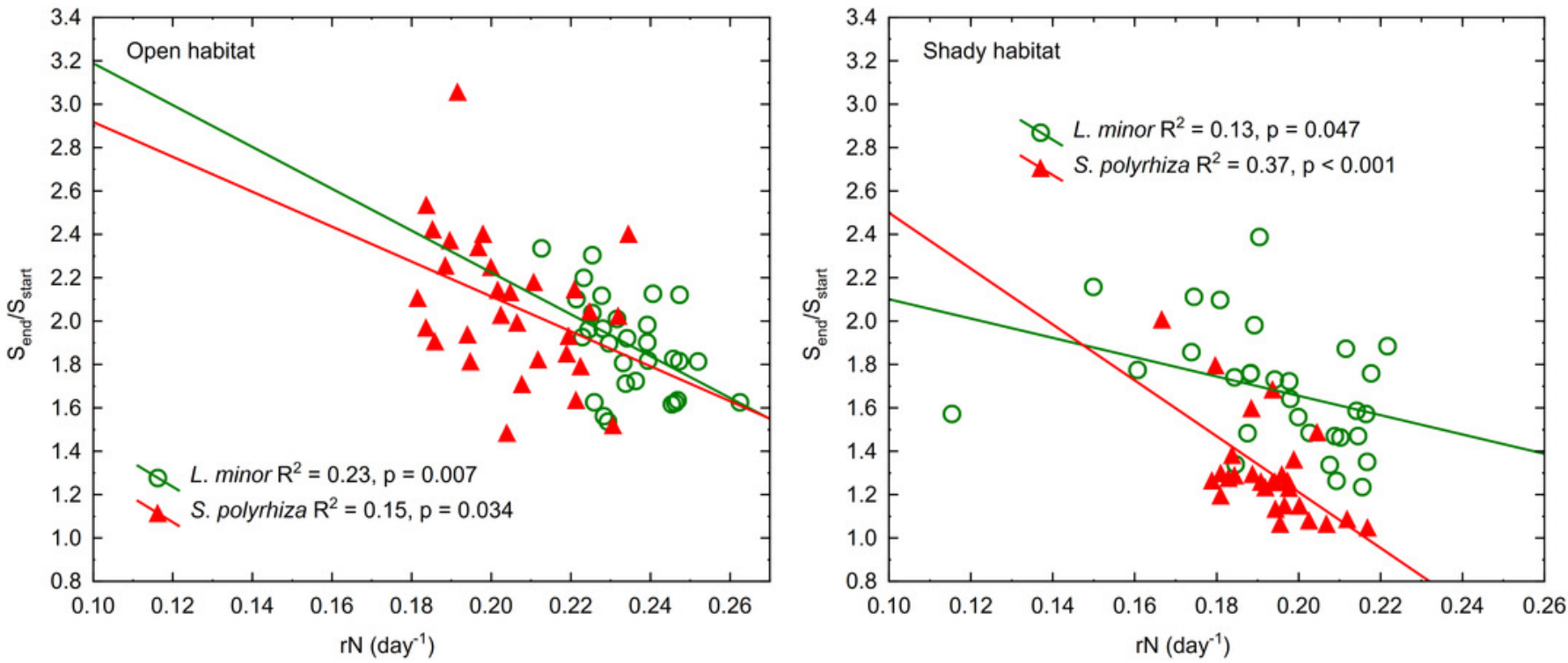


\section{Figure 5}

Effect of habitat-species interaction on the concentration of chlorophyll a in L. minor and S. polyrhiza. Each box combines initial concentrations and experimental data from three light intensities.

Different letters denote statistically significant differences in Tukey test $(p=0.002)$ following three-way ANOVA - see Table 3.

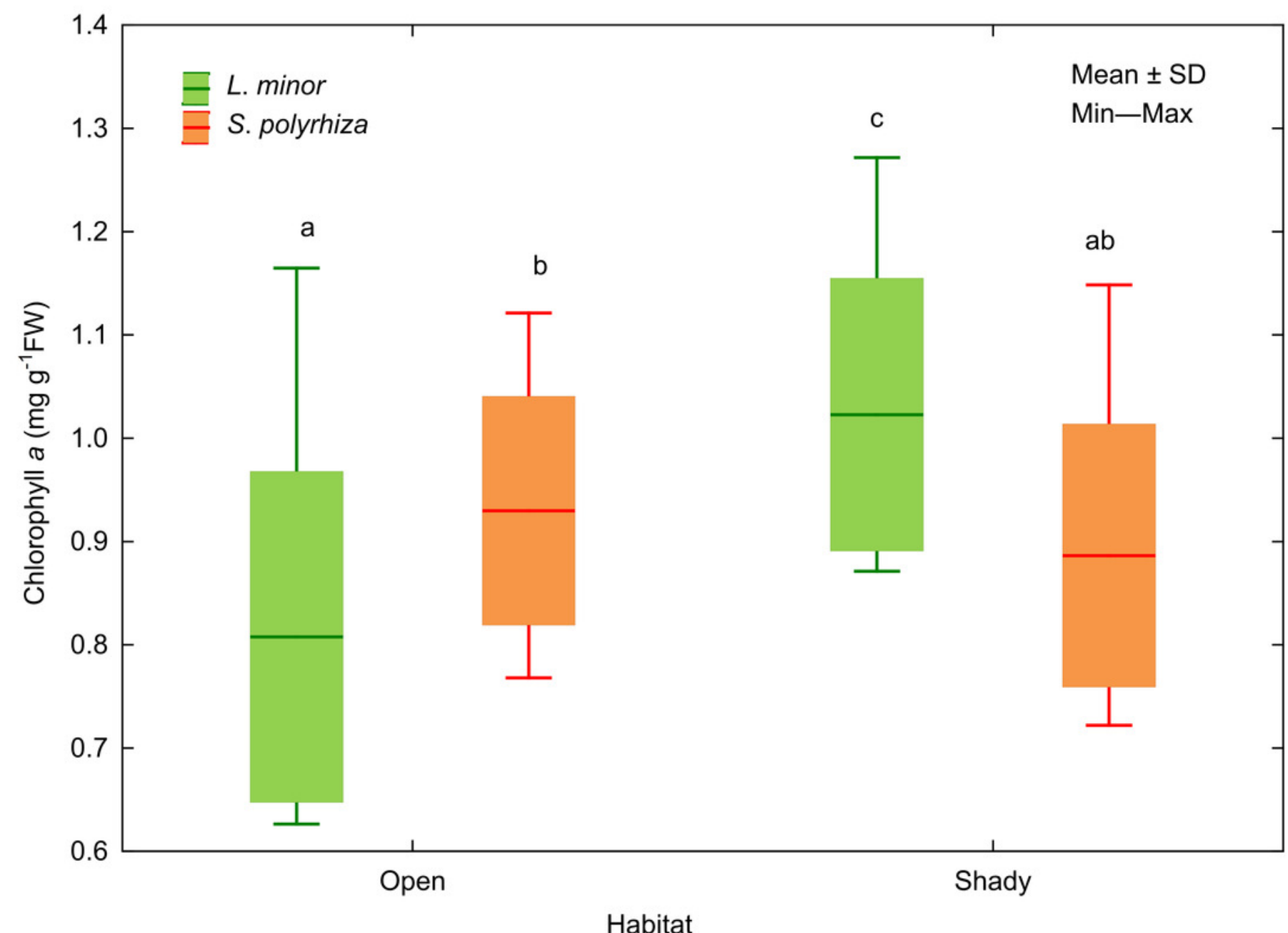




\section{Table $\mathbf{1}$ (on next page)}

Effect of light intensity (low, medium, high), habitat (open or shady), species and their interactions on the growth rates of $L$. minor and S. polyrhiza (MANOVA).

Light intensities: low -125 , medium -236 and high $-459 \mu \mathrm{mol}$ photons $\mathrm{m}^{-2} \mathrm{~s}^{-1}$. Statistically significant effects are indicated in bold. 


\begin{tabular}{|l|c|c|c|c|}
\hline Factors & F & Df effect & Df error & $\mathrm{p}$ \\
\hline Light intensity & 10 & 4 & 214 & $<\mathbf{0 . 0 0 1}$ \\
\hline Habitat & 178 & 2 & 107 & $<\mathbf{0 . 0 0 1}$ \\
\hline Species & 44 & 2 & 107 & $<\mathbf{0 . 0 0 1}$ \\
\hline Light intensity * habitat & 1 & 4 & 214 & 0.66 \\
\hline Light intensity * species & 12 & 4 & 214 & $<\mathbf{0 . 0 0 1}$ \\
\hline Habitat * species & 27 & 2 & 107 & $<\mathbf{0 . 0 0 1}$ \\
\hline Light intensity * habitat * species & 1 & 4 & 214 & 0.47 \\
\hline
\end{tabular}

1 


\section{Table 2 (on next page)}

Medians of the difference $(\Delta r)$ between the growth rate based on the surface area of fronds $(\mathrm{rS})$ and the number of fronds $(\mathrm{rN})$ in L. minor and S. polyrhiza from the open and shady habitats grown at different light intensities.

Light intensities: low - 125, medium - 236 and high $-459 \mu$ mol photons $\mathrm{m}^{-2} \mathrm{~s}^{-1}$. The significance of differences in the investment into the two growth parameters of both plants was checked by Dunn test following Kruskal-Wallis ANOVA $\left(\mathrm{H}_{11,120}=74.73, \mathrm{p}<0.001\right)$ and marked with different letters $(p<0.05)$. 


\begin{tabular}{|l|c|c|c|}
\hline \multirow{2}{*}{ Species } & Light & \multicolumn{2}{|c|}{$\Delta \mathrm{r}$} \\
\cline { 3 - 4 } & intensity & Open & Shady \\
\hline \multirow{3}{*}{ L. minor } & low & $0.043^{\text {ah }}$ & $0.041^{\text {ab }}$ \\
\cline { 2 - 4 } & medium & $0.035^{\text {aeh }}$ & $0.035^{\text {abd }}$ \\
\cline { 2 - 4 } & high & $0.037^{\text {afgh }}$ & $0.024^{\text {bef }}$ \\
\hline \multirow{3}{*}{ S. polyrhiza } & low & $0.040^{\text {afh }}$ & $0.014^{\text {cde }}$ \\
\cline { 2 - 4 } & medium & $0.044^{\text {ah }}$ & $0.014^{\text {cdeg }}$ \\
\cline { 2 - 4 } & high & $0.049^{\text {a }}$ & $0.018^{\text {bch }}$ \\
\hline
\end{tabular}

1 


\section{Table 3 (on next page)}

Effect of light intensity (low, medium, high), habitat (open or shady), species (L. minor, S. polyrhiza) and their interactions on chlorophyll a concentrations in the studied plants (three-way ANOVA).

Light intensities: low -125 , medium -236 and high $-459 \mu$ mol photons $\mathrm{m}^{-2} \mathrm{~s}^{-1}$. Statistically significant effects are indicated in bold. 


\begin{tabular}{|l|c|c|c|c|c|}
\hline Factors & SS & df & MS & F & $\mathrm{p}$ \\
\hline Light intensity & 554434 & 3 & 184811 & 35.43 & $<\mathbf{0 . 0 0 1}$ \\
\hline Habitat & 88696 & 1 & 88696 & 17.00 & $<\mathbf{0 . 0 0 1}$ \\
\hline Species & 608 & 1 & 608 & 0.12 & 0.74 \\
\hline Light intensity * habitat & 38097 & 3 & 12699 & 2.43 & 0.08 \\
\hline Light intensity * species & 16601 & 3 & 5534 & 1.06 & 0.38 \\
\hline Habitat * species & 200706 & 1 & 200706 & 38.48 & $<\mathbf{0 . 0 0 1}$ \\
\hline Light intensity * habitat* species & 12523 & 3 & 4174 & 0.80 & 0.50 \\
\hline Error & 166922 & 32 & 5216 & & \\
\hline
\end{tabular}

